\title{
Analisis Efektivitas Continuous Casting Machine 3 Menggunakan Overall Equipment Effectiveness pada PT. Krakatau Steel (Persero) Tbk
}

\author{
Julya Ditazha ${ }^{1)}$, Irwan Iftadi $^{2)}$ \\ Jurusan Teknik Industri, Fakultas Teknik, Universitas Sebelas Maret \\ Jln. Ir. Sutami No. 36 A, Surakarta, 57126, Indonesia ${ }^{1,2)}$ \\ E-Mail: julyaditazha@gmail.com ${ }^{1)}$,iftadi@gmail.com ${ }^{2}$
}

\begin{abstract}
ABSTRAK
PT. Krakatau Steel merupakan perusahaan yang bergerak dibidang produksi baja. Salah satu unit produksinya yaitu slab steel plant. Continuous casting machine, sebagai salah satu mesin yang terlibat dalam proses produksi slab steel, pada saat beroperasi sering mati mendadak, khususnya pada continuous casting machine 3 yang memiliki breakdown time terlama pada periode 2018, yakni sebesar 18.692 menit. Oleh karena itu, dibutuhkan perbaikan terhadap sistem pemeliharaan continuous casting machine 3 . Tujuan dari penelitian ini adalah untuk menganalisis efektifitas mesin dan menentukan usulan perbaikannya. Penelitian ini dilakukan dengan empat tahap, yaitu menentukan tingkat efektivitas mesin (OEE), menentukan nilai losses yang mempengaruhi rendahnya tingkat efektivitas dan menggunakan diagram pareto untuk mengetahui losses yang paling dominan, mengidentifikasi masalah yang menyebabkan losses dengan menggunakan diagram fishbone, dan memberikan usulan perbaikan. Hasil dari penelitian ini adalah didapatkan tingkat efektivitas mesin yang masih dibawah standard world class, yaitu sebesar 52,38\%, losses yang paling dominan adalah reduced speed losses dengan rata-rata sebesar $35,24 \%$, masalah-masalah yang ditemukan disebabkan oleh faktor manusia, mesin, dan lingkungan, serta usulan perbaikannya adalah dengan melakukan perbaikan pengalokasian operator pada setiap bagiannya, merevitalisasi mesin, dan melihat dokumen spesifikasi mesin sehingga dapat dilakukan pengecekan mesin secara rutin agar tidak overheat.
\end{abstract}

Kata kunci: Losses, Overall Equipment Effectiveness, Total Productive Maintenance

\section{Analysis of Overall Equipment Effectiveness on Continuous Casting Machine 3 in PT. Krakatau Steel (Persero) Tbk.}

\begin{abstract}
PT. Krakatau Steel is a company engaged in the field of steel production. One of the production units is a slab steel plant. Continuous casting machines, as one of the machines involved in the steel plate production process, got breakdown often while operates, especially on continuous casting machines 3 which have the longest breakdown time in 2018, which is 18,692 minutes. Therefore, repairs are needed for the continuous casting machine maintenance system 3. The purpose of this study is to analyze the machine's work effectiveness and determine the proposed improvement. This research was conducted using four steps, which are determining the level of effectiveness of the machine (OEE), determining the value of losses that affect the low level of effectiveness and using pareto diagrams to determine the most dominant losses, identifying problems that cause losses using fishbone diagrams, and provide proposed improvements. From this research, the effectiveness of the machine is still below the world class standard, which is $52.38 \%$, where the most dominant losses are reduced speed losses with an average of $35.24 \%$, problems found are caused by factors of man, machine and the environment, and the proposed improvement is by improving the allocation of operators in every part, revitalize the machine and machine specifications see the document so it can be checked regularly so that the engine does not overheat.
\end{abstract}

Keywords: Losses, Overall Equipment Effectiveness, Total Productive Maintenance 


\section{Pendahuluan}

PT. Krakatau Steel (Persero) Tbk merupakan Badan Usaha Milik Negara (BUMN) yang bergerak dibidang produksi baja. Perusahaan yang beroperasi di Cilegon ini memiliki tujuh unit produksi yang menghasilkan berbagai produk baja, yaitu Blast Furnace Complex (Hot Metal), Direct Reduction Plant (Iron Melting), Billet Steel Plant (Billet Steel), Slab Steel Plant (Slab Steel), Hot Strip Mill (produksi pengerolan baja lembaran panas), Cold Rolling Mill (produksi pengerolan baja lembaran dingin), dan Wire Road Mill (produksi batang kawat).

Unit produksi slab steel plant merupakan pabrik yang memproduksi lembaran baja yang berbentuk seperti kasur. Unit produksi slab steel plant terbagi menjadi dua, yaitu slab steel plant 1 dan slab steel plant 2 . Pada unit produksi slab steel plant terdapat tiga proses utama, yaitu proses primer, proses sekunder,

dan yang terakhir continuous casting. Pada proses continuous casting menggunakan mesin yang bernama continuous casting machine. Pada slab steel plant terdapat tiga buah continuous casting mechine. Continuous casting machine 1 dan 2 terdapat di slab steel plant 1, sedangkan continuous casting machine 3 terdapat di slab steel plant 2.

Pada kenyataan dilapangan continuous casting mechine mengalami mati mendadak (breakdown) dengan total waktu breakdown selama satu tahun pada CCM 1 sebesar 6.644 menit, CCM 2 sebesar 5.800 menit, dan CCM 3 sebesar 18.692 menit. Hal tersebut mengakibatkan berhentinya proses produksi sehingga proses produksi terhambat. Berikut merupakan tabel breakdown time Continuous Casting Machine, dimana pada bulan Juni tidak terdapat aktifitas produksi sehingga tidak memiliki data breakdown time.
Tabel 1. Breakdown Time Continuous

\begin{tabular}{cccc}
\hline Periode & $\begin{array}{c}\text { CCM 1 } \\
\text { (Menit) }\end{array}$ & $\begin{array}{c}\text { CCM 2 } \\
\text { (Menit) }\end{array}$ & $\begin{array}{c}\text { CCM 3 } \\
\text { (Menit) }\end{array}$ \\
\hline Mei-18 & 2285 & 1297 & 2245 \\
Jul-18 & 190 & 223 & 1353 \\
Agu-18 & 707 & 320 & 714 \\
Sep-18 & 1292 & 1520 & 3719 \\
Okt-18 & 1140 & 1420 & 4147 \\
Nov-18 & 20 & 220 & 3280 \\
Des-18 & 510 & 800 & 3234 \\
\hline Total & 6644 & 5800 & 18692 \\
\hline \multicolumn{5}{c}{ Casting Machine }
\end{tabular}

Pada tabel diatas terlihat bahwa pada continuous casting machine 3 memiliki breakdown time terlama. Sehingga, penelitian ini lebih difokuskan pada continuous casting machine 3. Teknik perawatan dan pemeliharaan secara menyeluruh yang dapat digunakan dalam melakukan identifikasi efektifitas suatu peralatan dan fasilitas yang dimiliki adalah dengan menggunakan pendekatan Total Productive Maintenance (TPM).

TPM dirancang untuk meningkatkan efektivitas dan efisiensi dari suatu mesin dan dilakukan dengan keikutsertaan seluruh pekerja dari top management hingga low management. Menurut Gaikwad (2018), Implementasi TPM tidak hanya meningkatkan efisiensi dan efektivitas peralatan tetapi dalam saat yang sama menghasilkan pengurangan waktu siklus, pengurangan ukuran inventory, dan keluhan pelanggan.

Nakajima (1988) telah meluncurkan konsep Total Productive Management (TPM) dengan metrik kuantitatif, yaitu Overall Equipment Effectiveness (OEE) untuk mengukur produktivitas masing-masing peralatan di pabrik. OEE dianggap sebagai alat pengukuran yang mampu mengukur produktivias mesin dengan mempertimbangkan tiga komponen penting, yaitu ketersediaan, kinerja, dan kualitas suatu mesin, serta dapat memetakan kerugian (Charaf dan Ding, 2015). OEE bertujuan untuk meningkatkan efektivitas peralatan lini produksi sehingga mencapai volume yang lebih besar dengan hasil yang baik sehingga 
biaya produksi yang dikeluarkan lebih rendah (Purba et. al., 2018).

Setelah dilakukannya perhitungan OEE, maka dapat dilakukan perhitungan six big losses. Six big losses adalah perhitungan mesin yang mengakibatkan kerugian produktivitas bagi perusahaan yang sering disebabkan oleh penggunaan mesin/peralatan yang tidak efektif dan efisien (Hermanto, 2019). Perhitungan six big losses dilakukan untuk mengetahui kerugian terbesar apa yang mempengaruhi efektifitas suatu mesin produksi sehingga dapat diambil tindakan yang benar untuk melakukan perbaikan.

Beberapa penelitian yang bertujuan untuk mengetahui efektivitas mesin adalah penelitian yang dilakukan oleh Anthony (2019); Rahmad, Pratikto, dan Wahyudi (2012); Rinawati \& Dewi (2014); Diniaty \& Susanto (2017). Hasil dari penelitian tersebut adalah rata-rata nilai OEE masih dibawah standar dan selanjutnya mencari penyebab rendahnya nilai OEE dengan menggunakan diagram fishbone.

Selain itu, pada penelitian yang dilakukan oleh Supriyadi, Ramayanti, dan Afriyansyah (2017) didapatkan hasil penelitian adalah rata-rata nilai OEE masih dibawah standar dan selanjutnya mencari penyebab dengan menggunakan fuzzy failure mode dan effect analysis.

Pada penelitian ini memiliki tujuan untuk menganalisis penyebab rendahnya efektivitas mesin, dan memberikan usulan perbaikan. Kontribusi dari penelitian ini adalah sebagai masukan kepada perusahaan mengenai efektivitas mesin, memberikan masukan kepada perusahaan dalam hal perawatan mesin, menambah pengetahuan pembaca, dan perkembangan ilmu pengetahuan.

\section{Metodologi}

Langkah pertama yang dilakukan pada penelitian ini adalah mengumpulkan data available time, planned downtime, breakdown time, setup time, data deffect, dan yang terakhir jumlah produksi pada continuous casting machine 3. Data yang diperlukan tersebut didapatkan dari divisi statistik slab steel plant.
Langkah berikutnya, yaitu menghitung nilai OEE. OEE berfungsi untuk mengukur sejauh mana peralatan melakukan apa yang seharusnya dilakukan, berdasarkan availability, performance, dan quality rate (Williamson, 2006). Untuk menghitung nilai OEE, maka perlu diketahui terlebih dahulu nilai-nilai dari availability rate, performance rate, dan rate of quality. Berikut merupakan formula untuk menghitung nilai availability, performance, quality rate.

Availability rate $=$

$\frac{\text { operating time }}{\text { Loading time }} \times 100 \%$

Performance Rate $=$

$\frac{T P P \times I C T}{\text { operating Time }} \times 100 \%$

Rate of Quality =

$\frac{T P P-\text { Defect Amount }}{T P P} \times 100 \%$

Keterangan :

TPP = Total Product Processed

ICT = Ideal Cycle Time

Sehingga, nilai OEE dapat diperoleh dengan mengalikan tiga komponen tersebut. Berikut merupakan formula untuk menghitung nilai OEE.

$$
\begin{aligned}
& \mathrm{OEE}(\%)=\text { Availability }(\%) x \text { Performance }(\%) \\
& x \text { Quality }(\%) \text {... }
\end{aligned}
$$

Standar nilai Overall Equipment Effectivenes (OEE) yang telah ditetapkan oleh Japan Institute of Plant Maintenance (JIPM) dan yang juga digunakan oleh PT. Krakatau Steel Tbk adalah sebagai berikut.

Tabel 2. Standar Nilai OEE

\begin{tabular}{cc}
\hline Faktor OEE & Standar Nilai \\
\hline Availability Rate & $90 \%$ \\
Performance Rate & $95 \%$ \\
Rate of Quality & $99 \%$ \\
OEE & $85 \%$ \\
\hline
\end{tabular}

Langkah selanjutnya adalah melakukan perhitungan six big losses. Perhitungan six big losses digunakan untuk mengetahui penyebab 
utama yang mengakibatkan efektivitas sebuah mesin/peralatan tidak optimal.

Kemudian menganalisis dan menginterpretasi hasil yang telah didapatkan dari hasil perhitungan sebelumnya. Untuk mengetahui penyebab dari faktor utama six big losses, dilakukan analisis dengan menggunakan diagram fishbone.

Langkah terakhir dalam penelitian ini adalah menarik kesimpulan dan saran. Kesimpulan merupakan pernyataan singkat dari keseluruhan isi, sedangkan saran adalah usulan yang diberikan oleh peneliti.

\section{Hasil dan Pembahasan}

\subsection{Perhitungan Availability Rate}

Availability digunakan untuk memastikan bahwa berbagai peralatan siap untuk digunakan bila diperlukan atau siap untuk digunakan setiap saat (Prasetyawan et. al., 2017). Loading time merupakan hasil pengurangan available time dan planned downtime. Berikut merupakan contoh perhitungan dari availability rate pada bulan Mei 2018 di PT. Krakatau Steel (Persero) Tbk.

Available rate

$$
\begin{aligned}
& =\frac{\text { Loading Time-Breakdown Time }}{\text { Available Time-Planned Downtime }} \times 100 \% \\
& =\frac{29945-2245}{44640-14695} \times 100 \% \\
& =92,50 \%
\end{aligned}
$$

Sehingga hasil perhitungan avaiability rate untuk setiap bulan pada periode tahun 2018 dapat dilihat pada Tabel 3.

\subsection{Perhitungan Performance Rate}

Performance digunakan untuk memastikan bahwa sistem produksi berjalan pada tingkat yang diharapkan atau bahkan kecepatan yang lebih cepat (Prasetyawan et. al., 2017). Berikut merupakan contoh perhitungan dari performance rate pada bulan Mei 2018 di PT. Krakatau Steel (Persero) Tbk.

$$
\begin{aligned}
& \text { Performance rate } \\
& =\frac{\text { TPP } \times I C T}{\text { Operating Time }} \times 100 \% \\
& =\frac{T P P \times \frac{\text { Kapasitas produksi/hari }}{\text { Jam kerja } / \text { hari }}}{\text { operating Time }} \times 100 \% \\
& =\frac{17352,86 \text { ton } \times \frac{1935,484 \text { ton }}{1440 \text { menit }}}{27700 \text { menit }} \times 100 \% \\
& =\frac{17352,86 \text { ton } \times 0,74 \text { menit } / \text { ton }}{27700 \text { menit }} \times 100 \% \\
& =46,61 \%
\end{aligned}
$$

Sehingga hasil perhitungan performance rate untuk setiap bulan pada periode tahun 2018 dapat dilihat pada Tabel 4.

Tabel 3. Hasil Perhitungan Availability Rate

\begin{tabular}{ccccc}
\hline Periode & $\begin{array}{c}\text { Available } \\
\text { Time } \\
\text { (Menit) }\end{array}$ & $\begin{array}{c}\text { Planned } \\
\text { Downtime } \\
\text { (Menit) }\end{array}$ & $\begin{array}{c}\text { Breakdown } \\
\text { time } \\
\text { (Menit) }\end{array}$ & $\begin{array}{c}\text { Availability } \\
\text { Rate }\end{array}$ \\
\hline Mei-18 & 44640 & 14695 & 2245 & $92,50 \%$ \\
Jul-18 & 44640 & 24464 & 1353 & $93,29 \%$ \\
Agu-18 & 44640 & 19081 & 714 & $97,21 \%$ \\
Sep-18 & 43200 & 5126 & 3719 & $90,23 \%$ \\
Okt-18 & 44640 & 10326 & 4147 & $87,91 \%$ \\
Nov-18 & 43200 & 21666 & 3280 & $84,77 \%$ \\
Des-18 & 44640 & 26671 & 3234 & $82,00 \%$ \\
\hline \multicolumn{5}{c}{ Rata-rata } \\
\hline
\end{tabular}


Tabel 4. Hasil Perhitungan Performance Rate

\begin{tabular}{ccccc}
\hline Periode & $\begin{array}{c}\text { Total } \\
\text { Product } \\
\text { Processed } \\
\text { (Ton) }\end{array}$ & $\begin{array}{c}\text { Operating } \\
\text { Time } \\
\text { (Menit) }\end{array}$ & $\begin{array}{c}\text { Ideal Cycle } \\
\text { Time } \\
\text { (Menit/Ton) }\end{array}$ & $\begin{array}{c}\text { Performance } \\
\text { Rate }\end{array}$ \\
\hline Mei-18 & 17352,86 & 27700 & 0,74 & $46,61 \%$ \\
Jul-18 & 12728,04 & 18823 & 0,74 & $50,31 \%$ \\
Agu-18 & 17685,18 & 24845 & 0,74 & $52,96 \%$ \\
Sep-18 & 29365,02 & 34355 & 0,74 & $63,59 \%$ \\
Okt-18 & 25452,24 & 30167 & 0,74 & $62,77 \%$ \\
Nov-18 & 19387,19 & 18254 & 0,74 & $79,02 \%$ \\
Des-18 & 14527,22 & 14735 & 0,74 & $73,35 \%$ \\
\hline \multicolumn{5}{c}{ Rata-rata } \\
\hline
\end{tabular}

Tabel 5. Hasil Perhitungan Rate of Quality

\begin{tabular}{cccc}
\hline Periode & $\begin{array}{c}\text { Total Product } \\
\text { Processed } \\
\text { (Ton) }\end{array}$ & $\begin{array}{c}\text { Defect Amount } \\
\text { (Ton) }\end{array}$ & $\begin{array}{c}\text { Rate of } \\
\text { Quality }\end{array}$ \\
\hline Mei-18 & 17352,86 & 1048,11 & $93,96 \%$ \\
Jul-18 & 12728,04 & 800,59 & $93,71 \%$ \\
Agu-18 & 17685,18 & 525,25 & $97,03 \%$ \\
Sep-18 & 29365,02 & 845,71 & $97,12 \%$ \\
Okt-18 & 25452,24 & 934,10 & $96,33 \%$ \\
Nov-18 & 19387,19 & 686,31 & $96,46 \%$ \\
Des-18 & 14527,22 & 348,65 & $97,60 \%$ \\
\hline \multicolumn{4}{c}{} \\
\hline
\end{tabular}

\subsection{Perhitungan Rate of Quality}

Quality digunakan untuk memastikan bahwa semua bahan baku dalam kondisi baik dan dapat dikonversi menjadi barang jadi. Berikut merupakan contoh perhitungan dari rate of quality pada bulan Mei 2018 di PT. Krakatau Steel (Persero) Tbk.

Rate of Quality

$$
\begin{aligned}
& =\frac{T P P-\text { Defect Amount }}{T P P} \times 100 \% \\
& =\frac{17352,86 \text { ton }-1048,11 \text { ton }}{17352,86 \text { ton }} \times 100 \% \\
& =93,96 \%
\end{aligned}
$$

Sehingga hasil perhitungan rate of quality untuk setiap bulan pada periode tahun 2018 dapat dilihat pada Tabel 5.

\subsection{Analisis Overall Equipment} Effectiveness

Pengukuran Overall Equipment Effectiveness (OEE) terdari tiga faktor, yaitu availability, performance, dan quality. Berikut merupakan contoh perhitungan.

$$
\begin{aligned}
\text { OEE }= & \text { Availability }(\%) \times \text { Performance }(\%) \times \\
& \text { Quality }(\%) \\
= & 92,50 \% \times 46,61 \% \times 93,96 \% \\
= & 40,51 \%
\end{aligned}
$$

Tabel 6. menunjukkan hasil perhitungan OEE disetiap periode pada tahun 2018. 
Tabel 6. Hasil Perhitungan OEE

\begin{tabular}{ccccc}
\hline Periode & $\begin{array}{c}\text { Availability } \\
\text { Rate }\end{array}$ & $\begin{array}{c}\text { Performance } \\
\text { Rate }\end{array}$ & $\begin{array}{c}\text { Rate of } \\
\text { Quality }\end{array}$ & $\begin{array}{c}\text { Overall } \\
\text { Equipment } \\
\text { Effectiveness }\end{array}$ \\
\hline Mei-18 & $92,50 \%$ & $46,61 \%$ & $93,96 \%$ & $40,51 \%$ \\
Jul-18 & $93,29 \%$ & $50,31 \%$ & $93,71 \%$ & $43,98 \%$ \\
Agu-18 & $97,21 \%$ & $52,96 \%$ & $97,03 \%$ & $49,95 \%$ \\
Sep-18 & $90,23 \%$ & $63,59 \%$ & $97,12 \%$ & $55,73 \%$ \\
Okt-18 & $87,91 \%$ & $62,77 \%$ & $96,33 \%$ & $53,16 \%$ \\
Nov-18 & $84,77 \%$ & $79,02 \%$ & $96,46 \%$ & $64,61 \%$ \\
Des-18 & $82,00 \%$ & $73,35 \%$ & $97,60 \%$ & $58,71 \%$ \\
\hline \multicolumn{5}{c}{ Rata-rata } \\
\hline \multicolumn{5}{c}{}
\end{tabular}

Tabel 7. Hasil Perhitungan Six Big Losses

\begin{tabular}{cccc}
\hline Jenis Losses & Rata-rata & Persentase & $\begin{array}{c}\text { Persentase } \\
\text { Kumulatif }\end{array}$ \\
\hline $\begin{array}{c}\text { Reduced Speed Losses } \\
\quad 35,24 \%\end{array}$ & $51,69 \%$ & $51,69 \%$ \\
$\begin{array}{l}\text { Idling and Minor } \\
\text { Stoppage Losses }\end{array}$ & $17,57 \%$ & $25,78 \%$ & $77,47 \%$ \\
$\quad \begin{array}{c}\text { Breakdown Losses } \\
\begin{array}{c}\text { Setup and Adjustment } \\
\text { Losses }\end{array}\end{array}$ & $10,30 \%$ & $15,10 \%$ & $92,57 \%$ \\
$\begin{array}{c}\text { Rework Losses } \\
\text { Start up and Yeild } \\
\text { Losses }\end{array}$ & $2,98 \%$ & $4,38 \%$ & $96,95 \%$ \\
\hline Total & $0,00 \%$ & $0,00 \%$ & $100,00 \%$ \\
\hline
\end{tabular}

Berdasarkan hasil perhitungan OEE pada Tabel 6. diketahui bahwa persentase nilai OEE continuous casting machine 3 disetiap periode pada tahun 2018 masih dibawah standard word class, yaitu $85 \%$. Dari ketiga faktor yang mempengaruhi nilai OEE, nilai performance rate merupakan nilai yang paling rendah dibandingkan nilai availability rate dan rate of quality.

\subsection{Analisis Six Big Losses}

Kerugian adalah kegiatan yang menyerap sumber daya tanpa menciptakan value. Kerugian ini dikelompokkan dalam tiga kategori utama, yaitu downtime losses, speed losses, quality losses.
Tujuan dari perhitungan six big losses adalah agar perusahaan mengetahui penyebab yang paling dominan mengakibatkan rendahnya efektivitas dari mesin, sehingga dapat dilakukan perbaikan yang benar untuk meningkatkan nilai OEE dari mesin/peralatan tersebut. Data hasil perhitungan six big losses dapat dilihat pada Tabel 7.

Dari hasil persentase six big losses pada Tabel 7, dapat dibuat diagram pareto pada Gambar 1. Reduced speed losses menjadi kerugian yang sangat signifikan menyebabkan rendahnya nilai OEE pada continuous casting machine 3 dengan nilai rata-rata sebesar 35,24\%. Maka dari itu diperlukan perbaikan untuk meningkatkan nilai OEE. 


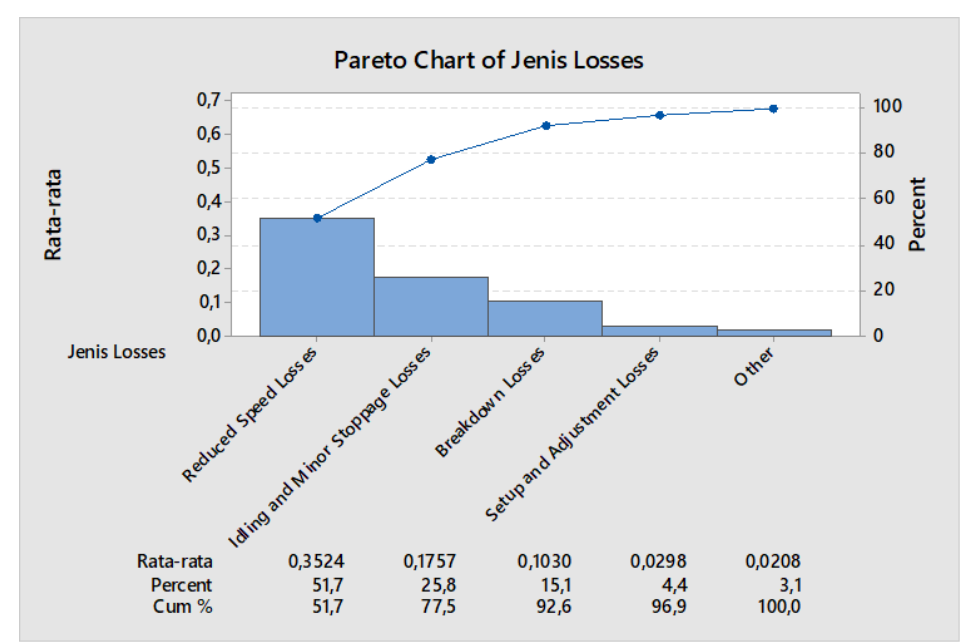

Gambar 1. Diagram Pareto Six Big Losses

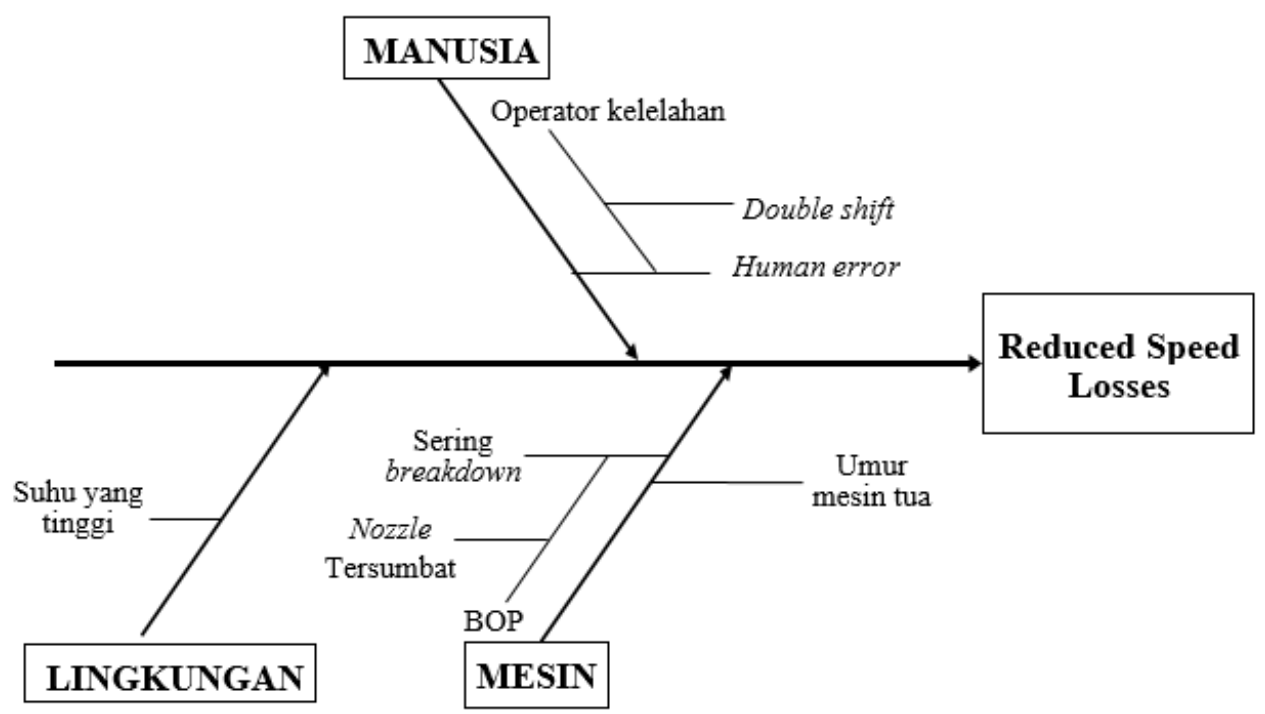

Gambar 2. Diagram Fishbone Six Big Losses

\subsection{Analisis Diagram Fishbone}

Berdasarkan prinsip diagram pareto diketahui bahwa $80 \%$ permasalahan yang ada hanya disebabkan oleh penyebab sebesar $20 \%$. Sehingga yang memiliki kontribusi terbesar terhadap rendahnya nilai OEE, yaitu reduce speed losses. Reduce speed losses adalah waktu yang terbuang ketika mesin atau proses berjalan di bawah speed capability atau siklus waktu ideal (waktu standar tercepat untuk memproduksi satu bagian). Hal ini berdampak pada berkurangnya jumlah produk yang dihasilkan. Berikut merupakan diagram fishbone dari reduced speed losses berdasarkan wawancara penulis dengan pihak divisi Maintenance Planning Control (MPC).

Faktor manusia yang menjadi penyebab terjadinya reduced speed losses adalah human error. Adapun penyebab terjadinya human error yaitu disebabkan karena operator kelelahan sehingga menyebabkan operator tersebut salah tekan saat mengoperasikan mesin. Kejadian salah tekan ini telah terjadi sebanyak 6 kali dalam pada periode 2018. Hal yang menyebabkan kelelahan adalah banyaknya operator yang pensiun. Pada dasarnya pekerja di PT. Krakatau Steel (Persero) Tbk itu banyak, hanya saja pengalokasian sumber daya manusianya yang kurang baik, sehingga operator yang tidak

pensiun kekurangan personil dan harus melakukan double shift agar mesin tetap dapat berjalan 24 jam. Kerja shift (bergilir) akan menggangu sirkadian tubuh. Gangguan ini akan berakibat terjadinya gangguan tidur pada pekerja dan dalam keadaan yang terjadi 
secara terus-menerus tanpa disertai perbaikan kondisi yang memadai menyebabkan kelelahan kronis (Fitriarni, 2013).

Faktor mesin yang menjadi penyebab terjadinya reduced speed losses adalah umur mesin yang sudah tua dan sering terjadinya breakdown pada mesin. Umur mesin yang sudah tua menyebabkan kurang optimalnya kecepatan proses produksi dari continuous casting machine 3 dalam menghasilkan suatu produk. Selain itu, jika ada spare part yang rusak sulit untuk menemukan penggantinya karena spare part obsolete sehingga saat ini sudah jarang dijual di pasaran. Adapun penyebab dari aspek mesin lainnya adalah seringnya terjadi breakdown. Breakdown pada continuous casting machine 3 keseringan terjadi karena BOP (Breakout Prediction). Penyebab terjadinya BOP karena pendinginan baja yang tidak sempurna saat didalam mesin, sehingga baja tersebut pecah. Hal ini biasanya terjadi karena adanya penyumbatan pada nozzle.

Faktor lingkungan yang menjadi penyebab terjadinya reduced speed losses, yaitu karena lingkungan sekitar continuous casting machine 3 yang memiliki suhu tinggi. Sehingga membuat kecapatan mesin semakin lama semakin menurun.

\subsection{Analisis Usulan Perbaikan}

Berdasarkan identifikasi akar penyebab masalah menggunakan fishbone diagram, maka diberikan usulan perbaikan yang dapat dilakukan untuk meningkatkan efektivitas mesin.

Dari faktor manusia, perbaikan yang dapat dilakukan adalah dengan melakukan perbaikan pengalokasian operator pada setiap bagiannya. Sehingga tidak terjadi double shift pada operator tersebut, karena menurut Ningsih dan Nimalasari (2018) semakin lama seseorang bekerja, maka kelelahan yang terjadi akan semakin sering. Menurut Hariandja (2002) dengan adanya alokasi operator dapat menimalkan gangguan pada rencana perusahaan sehingga tujuan perusahaan dapat tercapai.

Dari faktor mesin, perbaikan yang dapat dilakukan adalah dengan merevitalisasi mesin, sehingga memperlancar proses produksi. Selain itu, jika ada spare part yang rusak perusahaan tidak kesulitan untuk mencari pengganti dari spare part tersebut. Menurut penelitan yang telah dilakukan oleh Subiyanto (2014) revitalisasi mesin/alat pabrik akan memberikan dampak positif dengan indikasi adanya peningkatan setiap nilai elemen OEE.

Dari faktor lingkungan, perbaikan yang dapat dilakukan adalah dengan melihat dokumen spesifikasi suhu yang dapat diampu oleh mesin, sehingga dapat dilakukan pengecekan rutin agar mesin tidak overheat.

\section{Kesimpulan}

Dari penelitian ini dapat diambil kesimpulan, yakni sebagai berikut.

Selama periode bulan Mei, Juli, Agustus, September, Oktober, November, Desember 2018 diperoleh nilai OEE continuous casting machine 3 dengan rata-rata sebesar 52,38\%. Hal ini membuktikan bahwa continuous casting machine 3 selama tahun 2018 pengoperasiannya masih belum mencapai keadaan optimal. Terlihat dari nilai OEE yang diperoleh masih dibawah standard word class, yaitu $85 \%$.

Berdasarkan perhitungan six big losses, diperoleh losses yang paling dominan mempengaruhi rendahnya nilai OEE adalah reduced speed losses dengan rata-rata sebesar $35,24 \%$ yang disebabkan oleh faktor manusia, mesin, dan lingkungan.

Usulan perbaikan yang diberikan peneliti untuk perusahaan adalah dengan melakukan perbaikan pengalokasian operator pada setiap bagiannya, merevitalisasi mesin, dan melihat dokumen spesifikasi mesin sehingga dapat dilakukan pengecekan mesin agar tidak overheat.

\section{Daftar Pustaka}

Anthony, M. B. (2019). Analisis Penerapan Total Productive Maintenance (TPM) Menggunakan Overall Equipment Efectiveness (OEE) Dan Six Big Losses Pada Mesin Cold Leveller PT. KPS. JATI UNIK: Jurnal Ilmiah Teknik 
dan Manajemen Industri, Vol. 2, No. 2, 88-97.

Charaf, K., dan Ding, H. (2015). Is Overall Equipment Effectiveness (OEE) Universally Applicable? The Case of Saint-Gobain. International Journal of Economics and Finance, Vol.7, No.2, hal. 241-252.

Diniaty, D., \& Susanto R. (2017). Analisis Total Produktive Maintenance (TPM) pada Stasiun Kernel dengan Menggunakan Metode Overall Equipment Effectiveness (OEE) di PT. Surya Agrolika Reksa. Jurnal Teknik Industri: Jurnal Hasil Penelitian dan Karya Ilmiah dalam Bidang Teknik Industri, Vol. 3, No. 2, 66-70.

Fitriarni. 2013. Tinjauan Pola Kerja Shift Terhadap Pola Tidur, Pola Kehidupan Sosial, dan Keluarga serta Kelelahan di PT. Handaya Aneka Shoes Industry Tangerang. Skripsi. Jakarta: Universitas Indonesia.

Gaikwad, H. V. (2018). Total Productive Maintenance in a Manufacturing Industry : A Case Study of JISHU HOZEN Implementation. Indian Journal of Science and Technology, Vol. 11, No. 37, 7-13.

Hariandja, M.T.E. (2002). Manajemen Sumber Daya Manusia (Pengadaan, Pengembangan, Pengompensasian dan Peningkatan Produktivitas Pegawai). Jakarta: PT Grasindo.

Nakajima, S. (1988), Introduction to Total Productive Maintenance, Productivity Press, Inc., Cambridge : Massachusetts.

Ningsih, S. N. P. dan Nimalasari, N. (2018). Faktor yang Berhubungan dengan Kelelahan pada Pekerja Dipo Lokomotif PT. Kereta Api Indonesia (Persero). Journal of Industrial Hygiene and Occupational Health, Vol. 3, No. 1, 69-82.

Prasetyawan, Y., Suel, M., Claudia, L., dan Handayani, F.D. (2007). Targeting Overall Equipment Effectiveness for Small Medium Enterprise with Irregular Production System. International
Conference on Industrial and System Engineering, 1-7.

Purba, H. H., Wijayanto, E., Aristiara, N. (2018). Analysis of Overall Equipment Effectiveness (OEE) with Total Productive Maintenance Method on Jig Cutting: A Case Study in Manufacturing Industry. Journal of Scientific and Engineering Research, Vol. 5, No. 7, 397-406.

Rahmad, R., Pratikto, P., \& Wahyudi, S. (2012). Penerapan Overall Equipment Effectiveness (Oee) Dalam Implementasi Total Productive Maintenance (TPM)(Studi Kasus di Pabrik Gula PT."Y".). Rekayasa Mesin, Vol. 3 No. 3, 431-437.

Rinawati, D. I., \& Dewi, N. C. (2014). Analisis Penerapan Total Productive Maintenance (TPM) Menggunakan Overall Equipment Efectiveness (Oee) Dan Six Big Losses Pada Mesin Cavitec Di PT. Essentra Surabaya. Prosiding SNATIF, 21-26.

Subiyanto, S. (2014). Analisis Efektifitas Mesin/Alat Pabrik Gula Menggunakan Metode Overall Equipments Effectiveness. Jurnal Teknik Industri, Vol. 16, No. 1, 43-52.

Supriyadi, S., Ramayanti, G., \& Afriansyah, R. (2017). Analisis Total Productive Maintenance Dengan Metode Overall Equipment Effectiveness dan Fuzzy Failure Mode and Effects Analysis. Sinergi, Vol. 21, No. 3, 165172.

Williamson R.M. 2006. Using Overall Equipment Effectiveness: the Metric and the Measures. Columbus : Strategic Work Systems, Inc. 